\title{
Prevalence of abnormal uterine bleeding following cesarean section by double-layer interrupted closure of hysterotomy
}

\author{
Authors: Soromon Kataoka, Keiichiro Akabane, Tetsuya Nakajin, Yu Furuta, and Fumie \\ Tanuma
}

Institution: Hakodate Central General Hospital

\begin{abstract}
Problem Statement
Recent studies have indicated that surgical techniques used for closure of hysterotomy incision may affect uterine scar healing and have long-term consequences, specifically in terms of abnormal uterine bleeding.

Although there have been several reports of an association between abnormal bleeding and a niche at the uterine scar site, prospective studies on this problem in a random population are scarce. Voet et al. reported that niche prevalence was $64.5 \%$, with $22 \%$ categorized as large (defined as a residual myometrium thickness of $<50 \%$ of that of the adjacent myometrium). Additionally, postmenstrual spotting, defined as more than 2 days of brownish discharge after the end of the menstrual period, is more prevalent in patients with large niches than in patients with smaller niches. In the aforementioned study, uterine closure was mostly performed using the singlelayer technique. We previously reported that the incidence of large niche formation was significantly lower with double-layer closure than with single-layer closure, although double-layer closure did not decrease the overall incidence of niche formation. Therefore, we expect the prevalence of postmenstrual spotting to be lower in double-layer closures than in single-layer closures. We aimed to study the relationship between niche and postmenstrual spotting, and its prevalence, after cesarean section (CS) of a double-layer closure of hysterotomy.
\end{abstract}

\section{Methods}

A prospective cohort study of women undergoing CS with a transverse lower uterine segment incision was performed. The site of the cesarean scar was evaluated 6 months after CS with saline contrast sonohysterography. The niche depth and residual myometrium was measured and the ratio of the niche depth to the sum of the niche depth and residual myometrium thickness (niche ratio) was calculated. Bleeding pattern was assessed 12 months after CS.

\section{Results}

Fifty-four women were included. Niches were identified in 30/54 (55.6\%) women. A large niche (niche ratio $\geq$ $0.5)$ was observed in only one case (1.9\%). The prevalence of postmenstrual spotting at 12 months after CS was 4/54 (7.4\%).

Table 1 Frequency of the niches in relation to the number of previous cesarean sections

\begin{tabular}{ccc}
\hline $\begin{array}{c}\text { Number of } \\
\text { cesarean sections (n) }\end{array}$ & niches/patients & $\begin{array}{c}\text { niche } \\
\text { ratio } \geq 0.5\end{array}$ \\
\hline $1(n=40)$ & $19 / 40(47.5 \%)$ & $0 / 40(0.0 \%)$ \\
\hline $2(n=11)$ & $8 / 11(72.7 \%)$ & $1 / 11(1.9 \%)$ \\
\hline $3(n=3)$ & $3 / 3(100 \%)$ & $0 / 3(0.0 \%)$ \\
\hline
\end{tabular}

Table 2 Comparison of previous report and our study in relation to postmenstrual spotting

\begin{tabular}{lcc}
\hline & $\begin{array}{c}\text { van der Voet } \\
2014\end{array}$ & et \\
\hline uterine closure & mostly single layer & $\begin{array}{c}\text { interrupted } \\
\text { double-layer }\end{array}$ \\
niche $(\%)$ & $64.5 \%$ & $55.6 \%$ \\
$\begin{array}{l}\text { Large niche } \\
\text { (niche ratio } \geq 0.5)(\%)\end{array}$ & $22.0 \%$ & $1.9 \%$ \\
$\begin{array}{l}\text { postmenstrual } \\
\text { spotting }(\%)\end{array}$ & $20.3 \%$ & $7.4 \%$ \\
\hline
\end{tabular}

\section{Conclusion}

In our study, the prevalence of large niche and postmenstrual spotting after CS with double-layer closure was lower than that with single-layer closure previously reported. Double-layer closure may be associated with a lesser frequency of large uterine niches and postmenstrual spotting after CS. 